\title{
The impact of flood action groups on the uptake of flood management measures
}

\author{
Ruth Dittrich $^{1}$ • Anita Wreford ${ }^{1} \cdot$ Adam Butler $^{2}$ • \\ Dominic Moran ${ }^{1}$
}

Received: 25 November 2015 / Accepted: 8 July 2016/Published online: 3 August 2016

(C) The Author(s) 2016. This article is published with open access at Springerlink.com

\begin{abstract}
Household flood management measures can significantly reduce the risk from flooding. Understanding the factors that influence the uptake of measures has important implications for the design of measures to induce people to take charge of risk mitigation. We investigate the impact of flood action groups in communities in Scotland on the uptake of four measures: insurance, flood warnings, sandbags and floodgates applying regression analysis using a cross-sectional survey $(n=124)$. The groups were formed in response to the threat from flooding in those communities, and offer information and training on household flood management measures. We use the theoretical framework of Protection Motivation Theory, and compare uptake of the measures before and after the foundation of the flood action groups, as well as in the near future. The models show positive adoption effects for flood warnings, floodgates and to an extent for insurance, and a positive correlation with increased confidence of implementing and belief in the effectiveness of the measures. The effect is significant if specific information on the measures was provided, indicating the importance of
\end{abstract}

Electronic supplementary material The online version of this article (doi:10.1007/s10584-016-1752-8) contains supplementary material, which is available to authorized users.

Ruth Dittrich

Ruth.dittrich@sruc.ac.uk

Anita Wreford

anita.wreford@sruc.ac.uk

Adam Butler

adam.buttler@bioss.ac.uk

Dominic Moran

dominic.moran@sruc.ac.uk

1 SRUC, Land Economy, Environment and Society Research Group, Peter Wilson Building, West Mains Road, Edinburgh EH9 3JG, UK

2 BioSS, James Clerk Maxwell Bldg, King’s Buildings, Mayfield Rd, Edinburgh EH9 3JZ, UK 
tailored content. We conclude that appropriately designed flood action groups can be a costeffective way of increasing the uptake of household flood management measures.

\section{Introduction}

In Europe, storms and flooding are the most costly weather-related disasters, accounting for $77 \%$ (€282bn in 2005 value) of economic losses due to extreme weather events between 1980 and 2006 (CEA 2007). Beyond the economic losses, the recovery stage for flood victims often has important repercussions on family, health and work situations. Climate change may increase the frequency of high impact events locally in the future (IPCC 2012) and this may be exacerbated by development of housing in flood-prone areas (Bouwer et al. 2010) as well as impermeable surfaces such as streets and parking lots that increase runoff (Brattebo and Booth 2003). Taking the described factors together, implementing adaptation measures against flooding should be considered in vulnerable areas. This may require public flood protection - for example through integrated flood management strategies on a national and international level (European Union 2007, Scottish Government 2009) - but also adaptation measures implemented by households and firms where flood risk cannot be eliminated due to budget limitations. Private flood protection measures can reduce flood damage significantly (ICPR 2002, Kreibich et al. 2005), depending on the local conditions and the flood severity (Kreibich et al. 2015).

Yet practical experience suggests that households do not necessarily implement adaptation measures in order to increase their resilience to flooding (Kunreuther 1996, Peek and Mileti 2002, Bichard and Kazmierczak 2012). Research addressing household decision-making on flood prevention provides limited insights into the communication of flood risk (Dawson et al. 2011, Meyer et al. 2012, Kellens et al. 2013). There are an increasing number of studies highlighting the role of psychological factors in private adaptation to flooding in addition to risk perception and socio-economic variables. One approach, known as Protection Motivation Theory (PMT), attempts to reflect the main cognitive processes leading to the motivation to take protective action.

PMT suggests that individuals' decisions to take action is influenced not only by their evaluation of the physical risk, but also by their beliefs regarding the cost and effectiveness of the measure, as well as their confidence in implementing it. Several studies have found PMT a suitable framework for exploring flood adaptation behaviour (Grothmann and Reusswig 2006, Zaalberg et al. 2009, Bubeck et al. 2012b, Bubeck et al. 2013, Le Dang et al. 2014).

This study uses insights from PMT to explore the factors influencing the uptake of a range of household flood adaptation measures among 124 private households in Scotland. We add to the existing research by investigating the effect of flood action groups on uptake. These autonomous groups were founded in 2012 in small communities across Scotland with the aim of finding local solutions to flood risk, and provide information and training on a number of flood-related issues. The flood action groups are self-relying and run by community members. We specifically explore whether the groups have a direct impact on uptake and on people's perceptions of the effectiveness of measures and their confidence in implementing them - which according to PMT play an important role in determining flood adaptation behaviour. Thus, if the existence of flood action groups is shown to influence adaptation behaviour, this may indicate an effective, low-cost and relatively simple way to promote private flood adaptation.

The remainder of the article is structured as follows. Section 2 reviews the theoretical framework and relevant literature. Section 3 describes the data and the statistical model. The 
results are presented in Section 4 followed by a discussion of the practical implications for encouraging households to implement private flood management measures.

\section{Protection motivation theory and literature review}

PMT (Rogers 1975, Rogers 1983) was originally developed for protective behaviour to health threats and has been successfully extended to other threats including natural hazards such as flooding.

The model distinguishes two cognitive steps to describe the decision process when individuals evaluate a threat and possible coping measures: 'threat appraisal' and 'coping appraisal'. The former includes perceived risk and fear and describes how threatened the individual feels by a specific danger. Coping appraisal focuses on possible responses to address the risk and can be divided into three components. (Rogers and Prentice-Dunn 1997). First, 'response-efficacy' expresses how effectively the individual perceives the measure to reduce risk. 'Self-efficacy' describes whether the individual feels capable and confident to carry out the measure. Finally, 'response cost' refers to both the financial as well as the emotional cost of implementing the measure. Taken together, coping appraisal and threat appraisal influence the protection motivation of an individual, which is considered as the variable to induce, sustain and direct the activity of the individual to protect themselves (Maddux and Rogers 1983). The responses can be both protective and non-protective.

Protective responses are those that reduce the threat and will be enacted if high risk perceptions coincide with a strong coping appraisal. The answers respondents give may be non-protective if high risk perceptions go together with low coping appraisals (Rippetoe and Rogers 1987). Non-protective answers include wishful thinking, avoidance and denial.

Several empirical studies support the applicability of PMT to flooding: Grothmann and Reusswig (2006) applied PMT to flood adaptation behaviour of private households in Germany showing a good fit in contrast to socio-economic variables. Bubeck et al. (2013) showed that coping appraisal is an important variable in terms of precautionary behaviour among flood-prone households along the river Rhine. In particular, response efficacy and selfefficacy contribute to the models of flood-adaptation behaviour. Similar results were found in other studies (Botzen et al. 2009, Terpstra et al. 2009, Botzen and van den Bergh 2012) confirming the importance of the coping appraisal for adaptation intentions. Zaalberg et al. (2009) carried out a comparative study between flood victims and non-victims in the Netherlands, showing that exposure positively affects protective motivation for future flooding. In addition to the PMT variables, a number of other factors may influence uptake. These include flood experience (Grothmann and Patt 2005, Kreibich et al. 2005, Siegrist and Gutscher 2006) as well as social networks such as neighbours or friends having implemented measures (Bubeck et al. 2013), or public provision of flood risk adaptation measures inducing moral hazard (Le Dang et al. 2014).

A number of studies conclude that communication for flooding and adaptation should focus on explaining the potential measures as well as on information on how to implement them (Bubeck et al. 2013, Maidl and Buchecker 2014, Clayton et al. 2015). While several studies have found that increased knowledge and information correlate positively with precautionary behaviour (Thieken et al. 2006, Miceli et al. 2008), numerous studies found no evidence of a direct effect of information sources and flood adaptation behaviour when risk perception was controlled for (Zaleskiewicz et al. 2002, Grothmann and Reusswig 2006, Botzen et al. 2009). 
Behavioural decision research suggests that people may take action if they feel empowered to take charge rather than being treated as helpless citizens (Bush and Folger 1994, Page and Czuba 1999). Detailed, precise and personally relevant information might lead to more effective adaptation to flood risk (Klein 1998) such as proposing concrete easily implemented action which can alleviate the problem (Moser 2010).

Tentative evidence has been found for earthquake preparedness through targeted information campaigns (Lindell and Perry 2000). Further, communication research recognises that messenger choice is critical in the communications process (Moser 2010) and people are more likely to accept suggestions conveyed by people with similar views (Malka et al. 2009) such as peers as suggested by social learning theory (Bandura 1977).

We hypothesise that the activity of flood action groups works precisely through the mechanisms described above and can thus impact the motivation for implementing adaptation measures. The flood action groups provide information on a number of flood-related issues, including information and training on the use of flood adaptation measures, but also work as interest groups to lobby for flood protection schemes on the council level. They turn flooding into a locally relevant issue creating responsibility and ownership. In addition, flood action groups are locally grounded and people may thus be more likely to trust the recommended actions. Group members may influence neighbours and friends in the community who have been shown to be influential in PMT studies (Bubeck et al. 2013).

The hypothesised mechanisms within the PMT framework are presented in Fig. 1. The flood action groups may both affect the protection motivation directly but there may also be a mediating effect. The groups could positively impact self- and response-efficacy which in turn impact positively protection motivation.

The response variables within our analyses are household flood management measures. They include traditional measures, such as insurance and sandbags, but also more innovative and modern measures such as flood warnings and floodgates that have been specifically promoted or discussed by flood action groups.

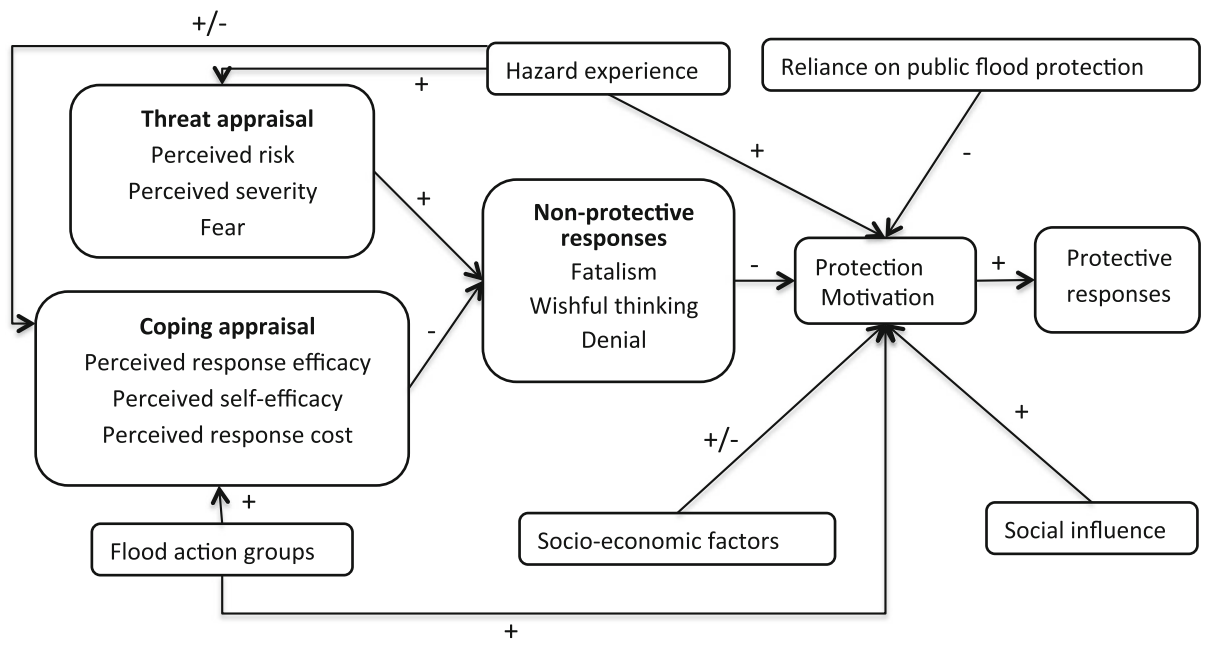

(Adapted from Grothmann and Reusswig, 2005)

Fig. 1 Conceptual framework for the data analysis' 
Flood insurance reduces the financial consequences of a flood once it occurs and is identified in other studies as an adaptation measure (Grothmann and Reusswig 2006, Bubeck et al. 2012b). Sandbags can slow down the penetration of water through buildings by acting as a barrier. Floodgates for households are installed in the case of flooding to hold back floodwater and generally provide very effective protection from flooding (SFF 2014). Flood warnings allow residents time to move valuable items to higher floors and to secure their properties with further measures.

In total 30 explanatory variables were gathered from the respondents based on the framework in Fig. 1, including their threat and coping appraisal, non-protective and protective responses, as well as socio-economic characteristics. Questions regarding financial aid by public authorities were included, which may provide a negative incentive to implement measures. Further, individuals may be influenced by neighbours and friends' adoption of measures (Ajzen 1991). Severity of experience of flooding in the near and distant past was also included as this has been observed to have positive effects on self-protective behaviour of natural hazards (Bubeck et al. 2012a). Finally, flood action group variables were included. Specifically, whether the respondents were aware of a flood action group in their community ('flood action group'), whether they were directly involved with the group ('involvement') as well as whether specific information was provided by the groups and whether the information was useful (see Table 1 for the different types of information and table A1 in the electronic supplementary material for a complete list of explanatory variables).

\section{Materials and methods}

Cross-sectional data from 124 private households across Scotland that have either experienced flooding or are at risk of flooding was gathered through a questionnaire-based survey and analysed with ordinal regression.

The questionnaire is based on the frameworks of Grothmann and Patt (2005) and Bubeck et al. (2013). It was refined with a pilot study of 18 flood risk households, and based on discussions with local flood groups and the Scottish Flood Forum (SFF) (an NGO that deals both with flood prevention and post-flood assistance). The results from the pilot study were used to further develop the questionnaire structure. The survey was distributed online and in paper format to 600 residents in 34 communities across Scotland where flooding has occurred in the past and thus flood action groups were formed since 2012. The survey was also distributed at a flood exhibition in Scotland to include respondents from communities without a flood action group and yielded a response rate of just over $20 \%$.

Table 1 shows a range of sample characteristics. All participants had experienced some flooding in the past and about $75 \%$ classified their flood experience as very severe. $85 \%$ of respondents have already implemented some form of flooding adaptation measure and $49 \%$ of participants confirmed they were actively involved in the community flood action groups. In the communities surveyed, the flood action groups provide information on the flood risk strategy of the local council (44\%), flood warnings (66\%), information on private flood management measures (56 \%) and, finally, information on how to use certain flood management measures $(44 \%)$. The sample characteristics are not perfectly representative of the Scottish population. For example, average age in the study are higher than in the overall population. The percentage of people over 65 is above the Scottish average (39\% in the sample versus $17 \%$ in the Scottish population (National Statistics 2014). However, over- 
Table 1 Sample characteristics $(n=124)$

\begin{tabular}{|c|c|c|c|}
\hline Variable & $\begin{array}{l}\text { Percentage of total } \\
\text { sample }\end{array}$ & Variable & $\begin{array}{l}\text { Percentage of total } \\
\text { sample }\end{array}$ \\
\hline Age & & Flood experience & \\
\hline $18-24$ & 1 & Yes & 100 \\
\hline $25-44$ & 16 & No & 0 \\
\hline $45-65$ & 44 & & \\
\hline \multirow[t]{2}{*}{$65+$} & 39 & Flood adaptation measure & \\
\hline & & Yes & 85 \\
\hline Gender & & No & 15 \\
\hline Female & 51 & & \\
\hline \multirow[t]{2}{*}{ Male } & 49 & Flood action group & \\
\hline & & Yes & 84 \\
\hline Income & & No & 16 \\
\hline$<£ 10,000$ & 12 & & \\
\hline$£ 10,000-19,999$ & 14 & $\begin{array}{l}\text { Involvement in flood action } \\
\text { group }\end{array}$ & \\
\hline$£ 20,000-29,999$ & 16 & Yes & 49 \\
\hline$£ 30,000-39,999$ & 10 & No & 51 \\
\hline$£ 40,000-49,999$ & 13 & & \\
\hline$£ 50,000-74,999$ & 17 & Information through group on & \\
\hline$£ 75,000-99,999$ & 9 & Flood risk strategy & 44 \\
\hline \multirow[t]{2}{*}{$>£ 100,000$} & 9 & Available measures & 56 \\
\hline & & Implementation of measures & 44 \\
\hline Education & & Flood warnings & 66 \\
\hline Secondary education & 29 & & \\
\hline $\begin{array}{l}\text { Diploma or vocational } \\
\text { degree }\end{array}$ & 22 & Usefulness of the information & \\
\hline Bachelor's degree & 32 & N/A & 33 \\
\hline Master's degree & 11 & Not useful & 6 \\
\hline \multirow[t]{2}{*}{ Doctorate } & 6 & 2 & 8 \\
\hline & & 3 & 11 \\
\hline Ownership & & 4 & 16 \\
\hline Tenant & 7 & Very useful & 27 \\
\hline Owner & 93 & & \\
\hline
\end{tabular}

representation of some population subgroups does not appear to affect estimates of means and proportions and is unlikely to affect correlation and regression analyses (Huang et al. 2012, Terpstra and Lindell 2013).

\subsection{Statistical model}

The response variables were measured on a five-point Likert-scale and we thus estimate the effect of the potential determining factors on the different adaptation measures by using an ordered-logit model (Christensen 2015). We provide a polychloric correlation matrix in the electronic supplementary material (table A3) for all dependent and independent variables 
which shows that the correlation between predictor variables included in the models is moderate (around 0.4). As the dataset is small and about $11 \%$ of the data per variable are missing due to non-responses, we used multiple imputation to compute the missing values stochastically in a way that accounts for uncertainty using the MICE package in R (Honaker et al. 2015) in order to improve the efficiency of estimation. We obtained five imputed datasets for our model selection. Despite the imputation, the observations to response variables ratio remains low, so backward selection is infeasible. For each of the response variables we therefore proceeded as follows: we entered each explanatory variable one at a time into an ordinal regression to determine which of the explanatory variables are significant at the $5 \%$ level. We created the model that contains all of these variables, and then performed backwards selection on this model using the Wald-test eliminating the least significant variables at each step, until all of the variables that remain within the model are significant at the $5 \%$ level.

The estimated regression coefficients are on the scale of the cumulative log odds; we present the exponential of these coefficients, which correspond to the cumulative odds, because these have a natural interpretation. For instance, we compare people who use flood warnings to an average extent ( 3 on the Likert scale) or less with people who use flood warnings more.

\subsection{Analytic methods}

We ran three regressions per measure: 1. implementation of the household flood adaptation measures prior to the foundation of the flood action groups as the response variable, 2 . implementation after the foundation of the flood action groups, 3. motivation for future implementation of measures. The latter two regressions included variables testing for the influence of the flood action groups to compare communities with and without flood action groups. For communities where flood action groups are in place, we tested for the influence of specific information provided by the groups.

We also ran a mediation analysis based on the standard approach of Baron and Kenny (1986) to explore whether the flood action groups variables $(\mathrm{X})$ may be correlated with either of the two components of the coping appraisal (Y) which in turn may be correlated with the uptake of the different measures $(Z)$. To test for partial and complete mediation, we verify whether there are significant relationships in regression equations between $X$ and $Y$ (with $Y$ being the outcome) and $\mathrm{X}$ and $\mathrm{Z}$ (with $\mathrm{Z}$ being the outcome). Then, we tested whether $\mathrm{Y}$ is related to $\mathrm{Z}$ while $\mathrm{X}$ is held constant. Additionally, we tested whether adding $X$ in the regression equation of $Z$ on $Y$ statistically significantly improves the model by using Wald tests to show partial mediation. If we find no added significance, this suggests complete mediation, i.e. the mediator 'absorbs' the effect of the flood action variables. We also tested for mediation of flood experience through threat and coping appraisal as hypothesised in Fig. 1. We provide McKelvey Zavoina $\mathrm{R}^{2}$ as goodness-of-fit measure.

The cross-sectional nature of data implies that the relationships should be interpreted as correlation rather than causation.

\section{Results and discussion}

Section 4.1 interprets the regression models for the four types of flood adaptation measures as well as the variables influencing response-efficacy and self-efficacy. Section 4.2 provides a short discussion. 


\subsection{Results}

Table 2 presents the results of the regression equations. Across the four measures, more explanatory variables fitted to data from respondents were identified for the more recent uptake of flood risk management measures as well as for intentions in the near future. This makes sense for two reasons. First, people may not remember the exact extent of their use of, for instance, sandbags prior to 2012, and it may have varied over the time period. Second, the dataset is cross-sectional apart from the response variables. The respondents' perception may have changed over time but also their socio-economic status, so we find a better fit regarding their current opinions/status, which is reflected in current uptake and intentions for future uptake in the present.

\subsubsection{Coping appraisal}

Self-efficacy is significant within at least one of the analyses for each measure. Response efficacy is significant for the use of insurance (D3 and D5) and flood warnings (A5). This confirms findings of other studies (Grothmann and Patt 2005, Zaalberg et al. 2009, Bubeck et al. 2013) showing that the belief in the effectiveness of a measure and the level of confidence to implement the measure play a central role in the uptake of household flood management measures. The third variable of coping appraisal, response cost appears to be mostly non-significant. An exception is the cost for flood warnings with a negative coefficient for intended uptake (A5) indicating a lower use with higher cost. This is a surprising result for a low cost measure such as flood warnings. It might reflect the cost of accessing flood warnings, mostly provided through text messages or the internet, which could be more challenging for the predominantly older respondents of the survey. Receiving financial support is not significant in the regressions. The lack of significance of response cost and financial support highlight that cost is mostly not decisive when it comes to encouraging the uptake of less expensive adaptation measures confirming the findings of Terpstra and Lindell (2013) and Lindell et al. (2009). While it is surprising that cost does not have a negative effect on insurance, conversations with the flood action groups indicated that all households are keen to obtain flood insurance (if provided by the insurance company) despite the high cost.

\subsubsection{Threat appraisal}

Risk perception, a component of threat appraisal, is significant for a number of the analyses. Some studies have found a minor contribution of risk perception (Bubeck et al. 2013, Koerth et al. 2013) while others observe a strong link between increased risk perception and increased uptake of measures (Miceli et al. 2008, Bichard and Kazmierczak 2012, Osberghaus 2015). Due to the different formulation of risk it is challenging to compare the results across studies. We find significance for risk in particular for floodgates (C3-C5) and sandbags (B2-B5). This high and significant risk perception for these two measures may be related to the fact that they represent physical actions to avoid homes being flooded; where respondents' decisions to implement these emergency measures reveal their perception that the risk is real and high. The results indicate that high risk perception may lead to increased flood preparedness but appears to depend on the measure. We do not find significance for fear as the second component of threat appraisal. 


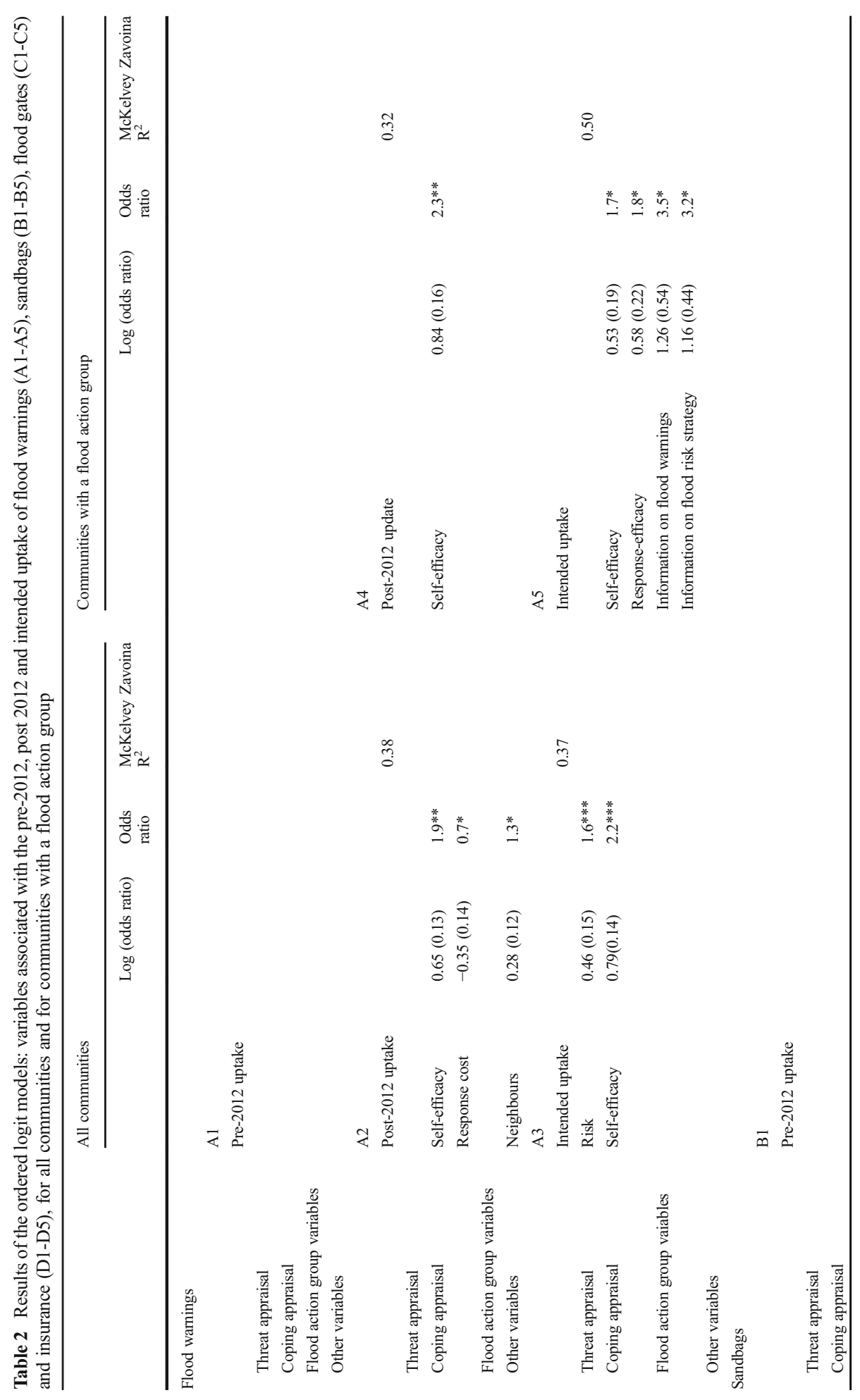




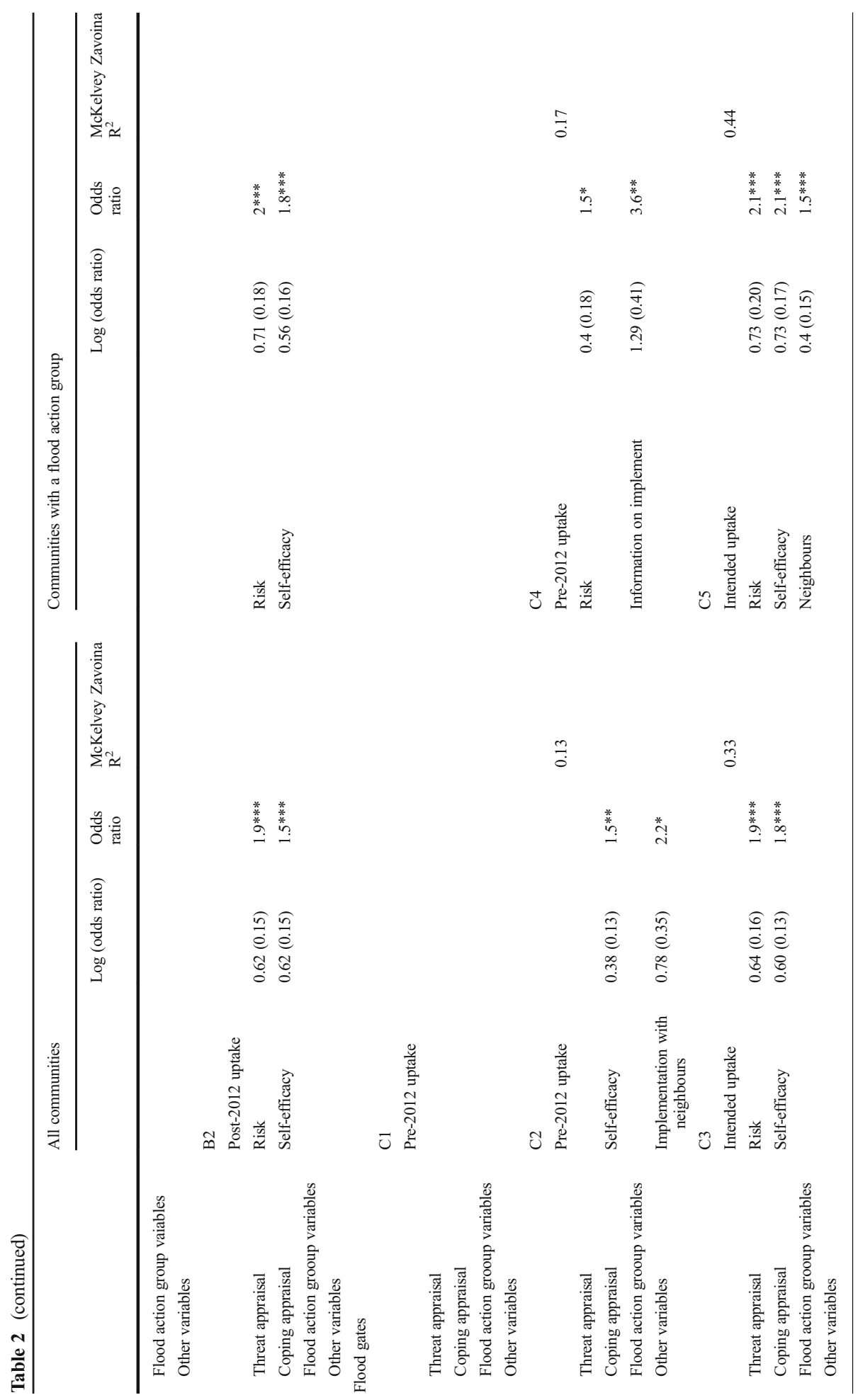




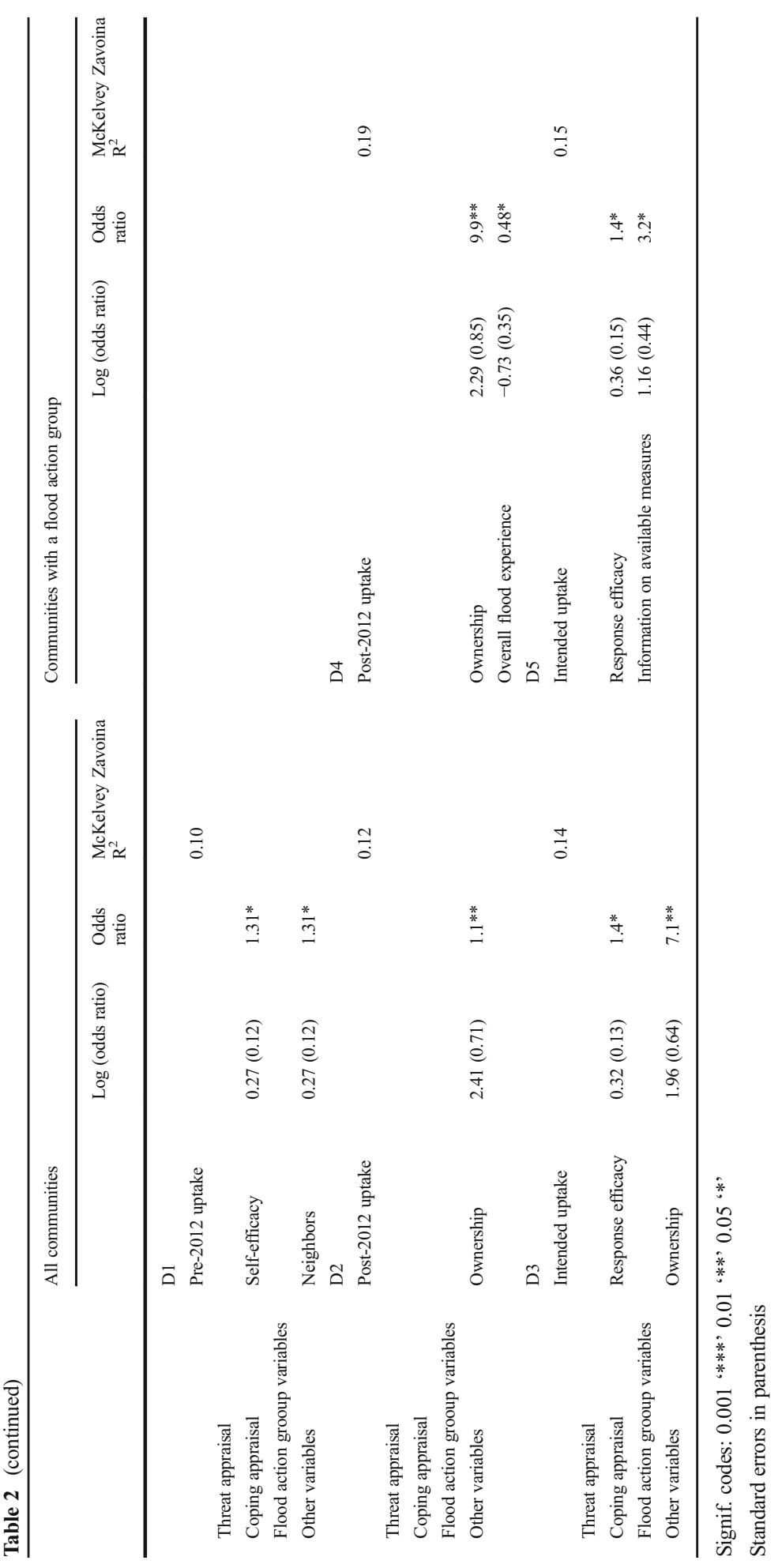




\subsubsection{Social environment, previous flood experience, socio-economic variables, non-protective answers}

We note the significance of neighbours in the use of insurance (D1), flood warnings (A2), floodgates (C2 and C4), as in other studies confirming the importance of the influence of peer behaviour (Bubeck et al. 2012a, Bubeck et al. 2013). For the use of floodgates post-2012 (C2), we find significance for the variable 'implementation with neighbour'. This likely reflects that non- or semi-detached houses require joint measures such as floodgates to protect the homes. Therefore, a respondent who has implemented a measure together with their neighbour is more likely to have set up a more sizeable floodgate.

Flood experience has only been found to be significant for the post-2012 insurance regression (D4) with a negative coefficient. The negative coefficients of flood experience is counter-intuitive, but other studies have found similar results (Kreibich et al. 2011b, Bubeck et al. 2013) and have been linked to higher insurance premiums due to an increased of risk to flooding. The lack of significance of flood experience for other variables may be explained by a complete mediation of experience on uptake through threat and coping appraisal (Bubeck et al. 2013). Indeed, in our mediation analysis, we find mediation effects for flood experience variables for floodgates (analyses E1 and E1 in Table 3) through both threat and coping appraisal and for sandbags for the former (analysis F1). For a complete list of the mediation results see table A4 in the electronic supplementary material.

In line with other studies (Grothmann and Reusswig 2006, Zaalberg et al. 2009, Bubeck et al. 2013, Osberghaus 2015), socio-economic variables explain relatively little of the data. Here, we only find that ownership positively influences the uptake of insurance (D2-D5) which is not surprising given the owners financial responsibility. Finally, we found no significance for non-protective responses once controlling for other variables.

\subsubsection{Flood action groups}

We find a positive relationship where flood action group variables contribute significantly to the explanation of the data (A5, C4, C5, D5), indicating that such groups may positively influence the uptake of household flood management measures. We find significant links for variables which represent specific information provided by the flood action groups and uptake of measures.

We can speculate about the direction of the effect for insurance due to the cross-sectional data: the variable 'having obtained information on available measures' is significant for the intended uptake of insurance for communities with a flood group present. This may reflect that people who are at risk of flooding and have an expensive insurance premium, or even struggle to obtain insurance, are more likely to obtain further information through the flood action groups. This was confirmed by talking to the flood action groups. The members aim to find other solutions to flood risk beyond insurance and indeed we find significant correlations between insurance and the other measures of between 0.3 and 0.7. These findings have been confirmed by other studies (Hudson et al. 2015, Lindell and Hwang 2008, Lindell et al. 2009). However, there may also be an exchange in the groups regarding the most appropriate insurance cover, which was also confirmed by the groups themselves, which may result in a more comprehensive cover for members.

For floodgates, we find a positive effect of factor 3.6 for post-2012 uptake if respondents received information on how to implement specific measures. The flood action group members confirmed in personal conversation that the setting up of floodgates was discussed and demonstrated as part of the flood action group activities. 


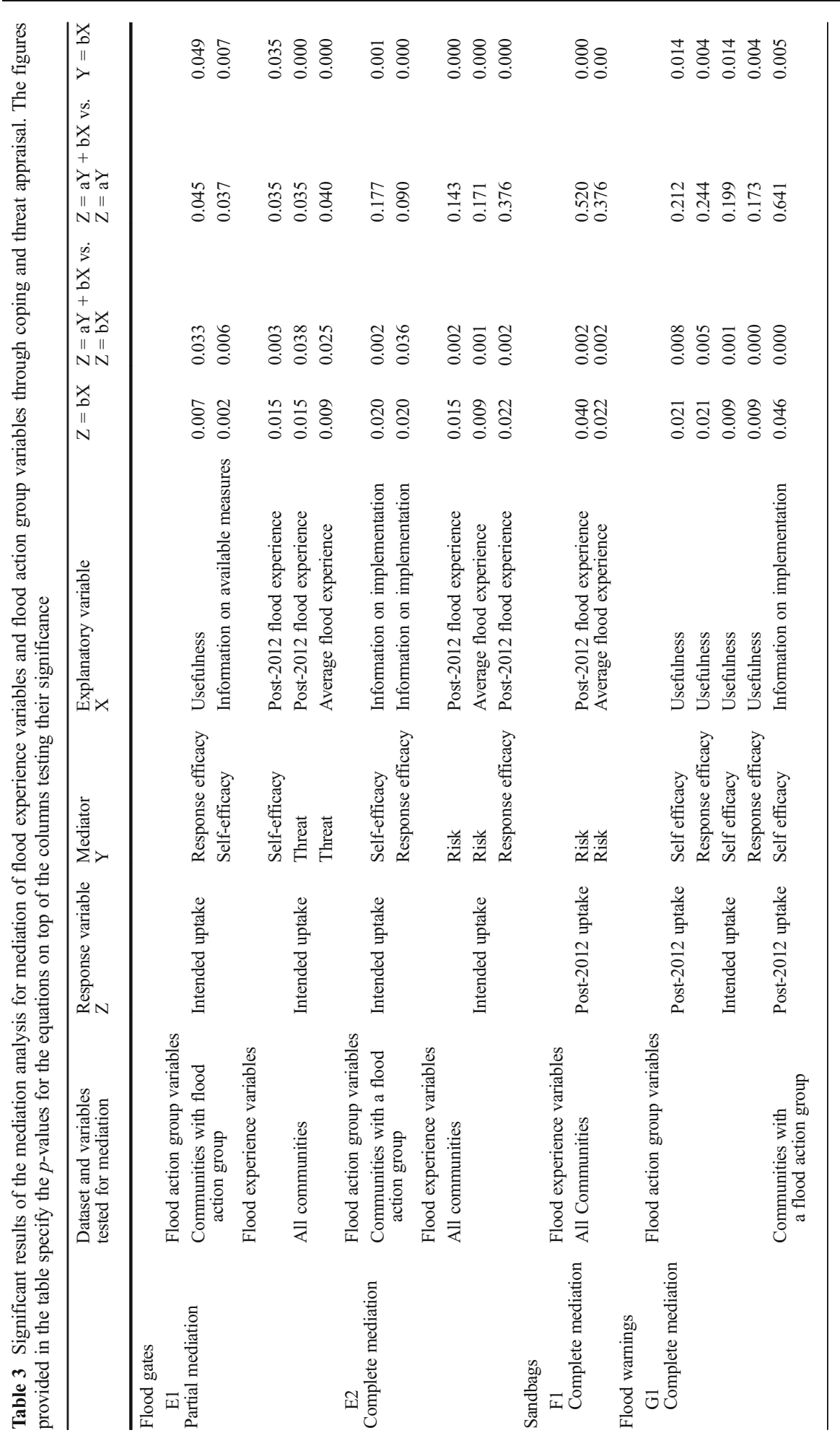




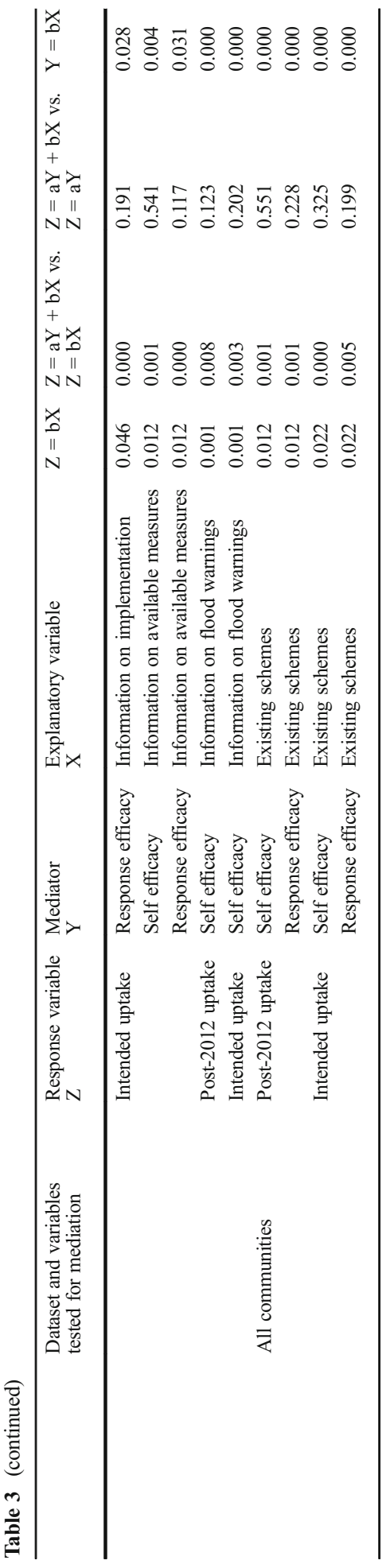

型 Springer 
For flood warnings, we find an increased likelihood of intended uptake of factor 3.5 if information on flood warnings was provided by the flood action group. Similarly, if respondents have received information about the flood risk strategy of their council, they have a higher likelihood of using flood warnings in the future. We can speculate whether this is due to local authorities recommending the use of flood warnings or the insight of the respondents that structural flood risk schemes may take considerable time to materialise. We find no link for sandbags. This may reflect that sandbags are long-standing household flood adaptation measures and the flood action groups cannot increase uptake. Indeed, about $60 \%$ of respondents already used sandbags in both samples before 2012 .

We find significant mediating effects of self-efficacy and response efficacy with respect to floodgates and flood warnings (analyses E1 and G1 in Table 3). For the uptake in the nearby future of floodgates, both partial and complete mediation are present if the obtained information from the group is perceived as 'useful', when 'information on available measures' has been provided. The number of significant mediating relationships is more extensive for flood warnings and applies to both post-2012 and intended uptake of flood warnings. The same variables as for floodgates are significant but in addition also whether 'information on flood warnings' have been provided and 'information on how to implement measures'.

There is also complete mediating effect of, 'existing schemes' for the use of flood warnings for the whole sample for post-2012 and intended uptake. Existing schemes refer to assistance (including that from flood action groups but also from the local council) with household flood management measures. While we cannot pin down the exact mechanism of 'existing schemes' on response and self-efficacy, we can deduce that specific help and information for flood risk at the household level appear to have a positive effect.

\subsection{Discussion}

The fitted models indicated a positive effect on uptake for insurance, floodgates and for flood warnings for flood action variables. It appears that having a flood action group in the community, or being involved in one, does not necessarily lead to an increased uptake of measures as the variable 'flood action group' and 'involvement' did not prove significant. It is rather when the groups provide tailored information such as on flood warnings or how to implement measures that significant correlations were observed.

We also find partial and complete mediating effects through the correlation of the flood action groups variables with increased self-efficacy and response-efficacy which are in turn associated with uptake. We detect significant correlations for floodgates and flood warnings which were promoted among the groups, if specific information had been provided which is also subsumed in the significance of the variable whether the obtained information is perceived as 'useful'. Thus, tailored information appear to positively impact the confidence in implementing these measures as well as the belief in their effectiveness. These coping appraisal variables are key for protection motivation as observed in our regressions and in other studies using PMT as theoretical framework.

The UK government encourages autonomous adaptation to climate change, with flooding being one of the major expected climate change impacts in the UK (Defra 2013). If the flood action groups can be 'kickstarted' with the help and direction of the council and the SFF their subsequent running will be ensured by the community itself, relying on active and engaged community members. The support of groups in the study by their local councils was limited to providing sandbags. While we do not have estimates of the costs of running flood action 
groups, we know that household flood management measures often exhibit high benefit-cost ratios (Holub and Fuchs 2008, Kreibich et al. 2011a), and would therefore expect its cost to be below that of a structural measure for the same benefit. Indeed, flood protection on the household level and supported by the community may prove to be the only viable solution for many small communities where larger structural flood defence measures will not pass a cost-benefit test due to a too small population.

A number of caveats need to be considered. First, the sample $(n=124)$ is very small, which sets a limit to the complexity of the model and the robustness of the inference. This highlights the importance of conducting research on a larger scale to confirm the results of the study. Second, a more comprehensive measure of risk perception would have been feasible and delivered different results. This includes, amongst others, dread and unknown risk (Fischhoff et al. 1978), and combining these with well known disaster risks (Trumbo et al. 2016) or people's expectations of the personal impacts caused by a disaster (Huang et al. 2012, Mileti and Peek 2000, Mileti and Sorensen 1987). Third, the changes in uptake of certain measures may also partly be due to external reasons not captured in the study, such as easier access to flood warnings or the challenge of obtaining flood insurance for certain high risk properties.

\section{Conclusion}

This study examined the factors influencing the uptake of four household flood adaptation measures in small communities around Scotland using a cross-sectional survey $(n=124)$ within an extended framework of PMT. The main focus was on testing whether local flood action groups, in which residents promote the deployment of flood management measures, have a positive effect on uptake. The fitted models indicated a positive effect for the use of insurance and of floodgates, if information on measures and implementation were provided; for flood warnings we detected a link if specific information on flood warnings were provided. Additionally, we found a mediating effect for flood warnings and floodgates: some flood action group variables appear to positively impact the coping appraisal variables which are key for protection motivation. We conclude that flood action groups may increase the uptake of precautionary measures in particular by providing specific information. Given limited resources of local authorities, the promotion of well-designed flood action groups might provide a cost-effective way of increasing household resilience to flooding in Scotland and elsewhere.

Open Access This article is distributed under the terms of the Creative Commons Attribution 4.0 International License (http://creativecommons.org/licenses/by/4.0/), which permits unrestricted use, distribution, and reproduction in any medium, provided you give appropriate credit to the original author(s) and the source, provide a link to the Creative Commons license, and indicate if changes were made.

\section{References}

Ajzen I (1991) The Theory of Planned Behavior. Organ Behav Hum Decis Process 50:179 Bandura A (1977) Social learning theory. Prentice-Hall, Englewood

Baron RM, Kenny DA (1986) The moderator-mediator variable distinction in social psychological research: conceptual, strategic, and statistical considerations. J Pers Soc Psychol 51:1173-1182 
Bichard E, Kazmierczak A (2012) Are homeowners willing to adapt to and mitigate the effects of climate change? Clim Chang 112(3):633-654

Botzen WJW, van den Bergh JCJM (2012) Monetary valuation of insurance against flood risk under climate change. Int Econ Rev 53:1005-1025

Botzen WJW, Aerts JCJH, van den Bergh JCJM (2009) Willingness of homeowners to mitigate climate risk through insurance. Ecol Econ 68:2265-2277

Bouwer LM, Bubeck P, Aerts JCJH (2010) Changes in future flood risk due to climate and development in a Dutch polder area. Glob Environ Chang 20:463-471

Brattebo BO, Booth DB (2003) Long- term stormwater quantity and quality performance of permeable pavement systems. Water Res 37:4369-4376

Bubeck P, Botzen WJW, Aerts JCJH (2012a) A review of risk perceptions and other factors that influence flood mitigation behavior. Risk Anal: An International Journal 32:1481-1495

Bubeck P, Botzen WJW, Kreibich H, Aerts JCJH (2012b) Long-term development and effectiveness of private flood mitigation measures: an analysis for the German part of the river Rhine. Nat Hazards Earth Syst Sci 12: 3507-3518

Bubeck P, Botzen WJW, Kreibich H, Aerts JCJH (2013) Detailed insights into the influence of flood-coping appraisals on mitigation behaviour. Glob Environ Chang 23(5):1327-1338

Bush RAB, Folger JP (1994) The promise of mediation: responding to conflict through empowerment and recognition. Jossey-Bass, San Francisco, CA

CEA (2007) Reducing the social and economic impact of climat change and natural catastrophes: insurance solutions and public private partnerships. Insurers of Europe, Brussels. Available at: https://circabc.europa. eu/webdav/CircaBC/MARE/steccostclimat/Library/overview_projects/sources_information/Reducing\% 20the $\% 20$ social\%20and\%20economic\%20impact\%20of\%20climate\%20change. Accessed 16 Jul 2016

Christensen RHB (2015) Regression Models for Ordinal Data. Package 'ordinal'. Version 2015.6-28. Available at: https://cran.rproject.org/web/packages/ordinal/ordinal.pdf. Accessed 16 Jul 2016

Clayton s, Devine-Wright p, Stern p C, Whitmarsh 1, Carrico a, Steg 1, Swim j, Bonnes M (2015) Psychological research and global climate change. Nat Clim Chang 5:640

Dawson R, Peppe R, Wang M (2011) An agent-based model for risk-based flood incident management. Nat Hazards 59:167-189

Defra (2013) The national adaptation programme. Making the country more resilient to a changing climate. The Stationary office, London

European Union (2007) Directive 2007/60/EC of the European Parliament and of the Council of 23 October 2007 on the assessment and management of flood risks, OJ L 288, 6.11.2007, p. 27-34.

Fischhoff B, Slovic P, Lichtenstein S, Read S, Combs B (1978) How safe is safe enough? A psychometric study of attitudes towards technological risks and benefits. Policy Sci 9:127-152

Grothmann T, Patt A (2005) Adaptive capacity and human cognition: the process of individual adaptation to climate change. Glob Environ Chang 15:199-213

Grothmann T, Reusswig F (2006) People at risk of flooding: why some residents take precautionary action while others do not. Nat Hazards 38:101-120

Holub M, Fuchs S 2008. Benefits of local structural protection to mitigate torrent-related hazards. In: Brebbia C \& Beriatos E (eds.) Risk Analylsis VI. WIT Press/WIT transaction on information and communication technologies

Honaker J, King G, Blackwell M (2015) Package Amelia. A program for missing data. https://cran.r-project.org/ web/packages/Amelia/Amelia.pdf

Huang S-K, Lindell MK, Prater CS, Wu H-C, Siebeneck LK (2012) Household Evacuation Decision Making in Response to Hurricane Ike. Nat Hazards Rev 13:283-296

Hudson P, Botzen W W, Czajkowski J Kreibich HK (2015) Adverse selection and moral hazard in natural disaster insurance markets: Empirical evidence from Germany and the United States. Available at http://www.aria.org. Accessed 19 Jul 2016

ICPR (2002) Non structural flood plain management: measures and their effectiveness. Koblenz: international commission for the protection of the rhine. http://www.iksr.org/en/documentsarchive/brochures/nonstructural-flood-plain-management/index.html?pdfPage=1. Accessed 17 Jul 2016

IPCC (2012) Managing the risks of extreme events and disasters to advance climate Change Adaptation. A Special Report of Working Groups I and II of the Intergovernmental Panel on Climate Change. Cambridge University Press, Cambridge

Kellens W, Terpstra T, de Maeyer P (2013) Perception and communication of flood risks: a systematic review of empirical research. Risk Anal: An International Journal 33:24-49

Klein RJT (1998) Towards better understanding, assessment and funding of climate adaptation. Change 44:15-19

Koerth J, Vafeidis A, Hinkel J, Sterr H (2013) What motivates coastal households to adapt pro-actively to sealevel rise and increasing flood risk? Reg Environ Chang 13:897-909 
Kreibich H, Thieken AH, Petrow T, Muller M, Merz B (2005) Flood loss reduction of private households due to building precautionary measures - lessons learned from the Elbe flood in August 2002. Nat Hazards Earth Syst Sci 5:117-126

Kreibich H, Christenberger S, Schwarze R (2011a) Economic motivation of households to undertake private precautionary measures against floods. Nat Hazards Earth Syst Sci 11:309-321

Kreibich H, Seifert I, Thieken AH, Lindquist E, Wagner K, Merz B (2011b) Recent changes in flood preparedness of private households and businesses in Germany. Reg Environ Chang 11:59-71

Kreibich H, Bubeck P, Vliet M, Moel H (2015) A review of damage- reducing measures to manage fluvial flood risks in a changing climate. Mitig Adapt Strateg Glob Chang 20:967-989

Kunreuther H (1996) Mitigating disaster losses through insurance. J Risk Uncertain 12(2):171-187

Le Dang H, Li E, Nuberg I, Bruwer J (2014) Understanding farmers' adaptation intention to climate change: a structural equation modelling study in the Mekong Delta, Vietnam. Environ Sci Pol 41:11-22

Lindell MK, Hwang SN (2008) Households' perceived personal risk and responses in a Multihazard environment. Risk Anal 28:539-556

Lindell MK, Perry RW (2000) Household adjustment to earthquake hazard: a review of research. Environ Behav 32:461-501

Lindell MK, Arlikatti S, Prater CS (2009) Why people do what they do to protect against earthquake risk: perceptions of hazard adjustment attributes. Risk Anal 29:1072-1088

Maddux JE, Rogers RW (1983) Protection motivation and self-efficacy: a revised theory of fear appeals and attitude change. J Exp Soc Psychol 19:469-479

Maidl E, Buchecker M (2014) Raising risk preparedness through flood risk communication. Natural Hazards and Earth System Sciences Discussions 2:167

Malka A, Krosnick JA, Langer G (2009) The Association of Knowledge with concern about global warming: trusted information sources shape public thinking. Risk Anal 29:633-647

Meyer V, Kuhlicke C, Luther J, Fuchs S, Priest S, Dorner W, Serrhini K, Pardoe J, Mccarthy S, Seidel J, Palka G, Unnerstall H, Viavattene C, Scheuer S (2012) Recommendations for the user-specific enhancement of flood maps. Nat Hazards Earth Syst Sci 12:1701-1716

Miceli R, SOTGIU I, Settanni M (2008) Disaster preparedness and perception of flood risk: a study in an alpine valley in Italy. J Environ Psychol 28:164-173

Mileti DS, Peek L (2000) The social psychology of public response to warnings of a nuclear power plant accident. J Hazard Mater 75:181-194

Mileti DS, Sorensen JH (1987) Why people take precautions against natural disasters. In: Weinstein N (ed) Taking care: Why people take precautions. Cambridge University Press, New York

Moser SC (2010) Communicating climate change: history, challenges, process and future directions. Wiley Interdiscip Rev Clim Chang 1:31-53

National Statistics (2014) Mid-2014 Population Estimates Scotland Population estimates by sex, age and administrative area. A National Statistics publication for Scotland, Edinburgh

Osberghaus D (2015) Analysis: The determinants of private flood mitigation measures in Germany — Evidence from a nationwide survey. Ecol Econ 110:36-50

Page N, Czuba C E 1999. Empowerment: What Is It? J Ext, 37

Peek LA, Mileti DS (2002) The history and future of disaster research. In: Bechtel R, Churchman A (eds) Handbook of environmental psychology. Wiley, New York

Rippetoe PA, Rogers RW (1987) Effects of Components of Protection-Motivation Theory on Adaptive and Maladaptive Coping With a Health Threat. J Pers Soc Psychol 52:596

Rogers RW (1975) A protection motivation theory of fear appeals and attitude change. J Psychol 91:93

Rogers RW 1983. Cognitive and physiological processes in fear appeals and attitude change: A revised theory of protection motivation. In: Cacioppo BL, Petty LL Social Psychophysiology: A sourcebook: Guilford

Rogers RW, Prentice-Dunn S (1997) Protection motivation theory. In: Gochman DS (ed) Handbook of Health Behavior Research I: Personal and Social Determinants. Plenum Press, New York

Scottish Government 2009. Flood risk management Act (Scotland) 2009. http://www.legislation.gov.uk/asp/ 2009/6/pdfs/asp_20090006_en.pdf.

Siegrist M, Gutscher H (2006) Flooding risks: a comparison of lay People's perceptions and Expert's assessments in Switzerland. Risk Anal: An International Journal 26:971-979

SFF (2014) Flood protection products. Scottish Flood Forum. Available at: http:/www.scottishfloodforum.org/ flood-protection/. Accessed 17 Jul 2016

Terpstra T, Lindell MK (2013) Citizens' perceptions of flood hazard adjustments: an application of the protective action decision model. Environ Behav 45:993-1018

Terpstra T, Lindell MK, Gutteling JM (2009) Does communicating (flood) risk affect (flood) risk perceptions? Results of a quasi-experimental study. Risk Anal: An International Journal 29:1141-1155 
Thieken AH, Petrow T, Kreibich H, Merz B (2006) Insurability and Mitigation of Flood Losses in Private Households in Germany. Risk Anal: An International Journal 26:383-395

Trumbo CW, Peek L, Meyer MA, Marlatt HL, Gruntfest E, Mcnoldy BD, Schubert WH (2016) A cognitiveaffective scale for hurricane risk perception. Risk Anal. doi:10.1111/risa.12575.

Zaalberg R, Midden C, Meijnders A, Mccalley T (2009) Prevention, Adaptation, and Threat Denial: Flooding Experiences in the Netherlands. Risk Analysis: An International Journal 29:1759-1778

Zaleskiewicz T, Piskorz Z, Borkowska A (2002) Fear or money? Decisions on insuring oneself against flooding. Risk, Decision and Policy 7:221-233 